\title{
DESIGN IMPROVEMENTS OF A GRIPPER-TYPE TRANSPLANTER FOR PINEAPPLE SUCKERS
}

\author{
Mohd Taufik Ahmad $^{1 *}$, Rohazrin Abdul Rani ${ }^{1}$ and Abd Rahim Hassan ${ }^{1}$ \\ ${ }^{1}$ Mechanization and Automation Research Center, MARDI HQ, \\ 43400 Serdang, Selangor, Malaysia. \\ *Email: taufik@mardi.gov.my \\ Phone: +603 8943 1468; Fax: +603 89482961
}

\begin{abstract}
Pineapple transplanting is very laborious work. This process requires 15 workers to plant one hectare of pineapple, which requires 43,500 suckers. The objective of this study was to develop an improved mechanical transplanter for transplanting pineapple suckers. Physical parameters of pineapple suckers, such as weight $(\mathrm{g})$, length $(\mathrm{cm})$, diameter $(\mathrm{cm})$ and canopy $(\mathrm{cm})$ were measured for two varieties, MD2 and N36. A preliminary experiment based on the gripper-type mechanical transplanter was also done. The experiment proved that this transplanter had potential for transplanting pineapple suckers, as it was able to transplant the suckers with the targeted planting distance of $30 \mathrm{~cm}$. However, components such as the roller chain system, the grippers and furrow opener required design improvements. The roller chain system should use $12.5 \mathrm{~mm}(0.5 \mathrm{in})$ chain for the whole chain-sprocket system. The gripper should be lengthened to $30 \mathrm{~cm}$ to accommodate the uniform pineapple sucker length. The gripper slot should also be widened to about $6 \mathrm{~cm}$. The furrow opener needs to be widened from $8.9 \mathrm{~cm}$ to $10.2 \mathrm{~cm}$ to accommodate the biggest diameter of pineapple suckers. It is hoped that these design improvements can improve the workability of the mechanical transplanter for transplantation of pineapple suckers
\end{abstract}

Keywords: Pineapple suckers; mechanized transplanting; gripper-type planting mechanism.

\section{INTRODUCTION}

Pineapple is one of the tropical fruits that has a bright future in supporting the Malaysian economy. Currently, 95\% of the domestic canned pinepapple production is used for the export market, while the rest is for the domestic market. Fresh pineapple contributes only $30 \%$ of the export market and $70 \%$ for the domestic market (MPIB, 2012). It is listed under NKEA for agriculture to increase production, targeting the export market especially in the Middle East and Europe. It is forecast that farmers would be enable to earn a monthly income of RM4500 per hectare and at the same time contribute RM1.6 billion to Gross National Income (GNI) (PEMANDU, 2011). A number of pineapple varieties are available in Malaysia. However, the MD2 and N36 varieties are both popular for export. MD2 is a variety developed by the Pineapple Research Institute, Hawaii that is yellow-gold in color, very sweet, fibrous and rich in vitamin C. N36 is a variety developed by the Malaysian Agricultural Research and Development Institute (MARDI). This variety has a pale yellow color and is resistant to black heart disease. MD2 has a more uniform shape than N36, but N36 is larger than MD2 (MPIB, 2013; JTP, 2013). To support the increase in production rate would require the planting density to be increased. A hectare of pineapple would require 
43,500 plants. A standard worker is only able to plant 3000 suckers/day. This means that 15 workers are required to plant one hectare of pineapple in one day. In addition, domestic labor is difficult to obtain. As a result, domestic agriculture is highly dependent on foreign labor. It is expected that mechanization would be the main enabling factor to support the increase in pineapple cultivation. MARDI has taken measures to handle this issue by developing a complete mechanized pineapple production package, which includes a mechanical transplanter. This machine is able to plant pineapple in 13 hours/ha. However, it would still require two operators at the rear to release the suckers from the transplanter bin and place them in the soil (Rahim et al.,2007; Rahim et al., 2013).

The existing transplanter has raised issues such as planting losses in the field and safety concerns. The current transplanter has a huge loading bin, and two operators sit at a low position near to the ground to grab pineapple suckers from the loading bin and position them in front of a mechanical soil puncher. This has created some safety concerns because the tractor driver has difficulty in seeing the transplanting operators from the tractor cabin because they are sitting at such a low position. The puncher creates a soil opening and a set of soil compacter wheels compact the soil after transplanting. During the transplanting process, unsuccessful planting occurs due to mis-planting or suckers not being planted in a vertical position. A gripper-type mechanical transplanter has been proposed to be used as a reference to improve the design of the pineapple transplanter. This machine was originally used to transplant sweet potato (Hamid et al., 2010). It is smaller than the pineapple transplanter, which means that the loading bin is smaller. This machine requires one operator to transfer the seedlings or cuttings from the loading tray to the grippers. The specific objective of this study was to develop an improved mechanical transplanter for pineapple suckers. Physical parameters of pineapple suckers from two varieties, MD2 and N36, were used. A preliminary experiment based on the gripper-type mechanical transplanter was done. Improvements were suggested based on these two activities.

\section{MATERIAL AND METHODS}

\section{Pineapple Suckers Physical Parameters}

Two varieties of pineapple suckers, MD2 and N36 were taken from the Malaysian Pineapple Industrial Board (MPIB) demonstration plot at the Malaysian AgroExposition Park Serdang (MAEPS), Selangor. Three grades were available for each variety, large (A), medium (B) and small (C), with 50 samples each. Sorting and marking with a permanent marker were done to differentiate the varieties and grades. Physical parameters of all the pineapple suckers, such as weight $(\mathrm{g})$, length $(\mathrm{cm})$, diameter $(\mathrm{cm})$ and canopy $(\mathrm{cm})$ were measured (Figure 2). The parameters were important to observe whether there were significant differences between grades from each variety and how these parameters affected the design of the transplanting machine. 


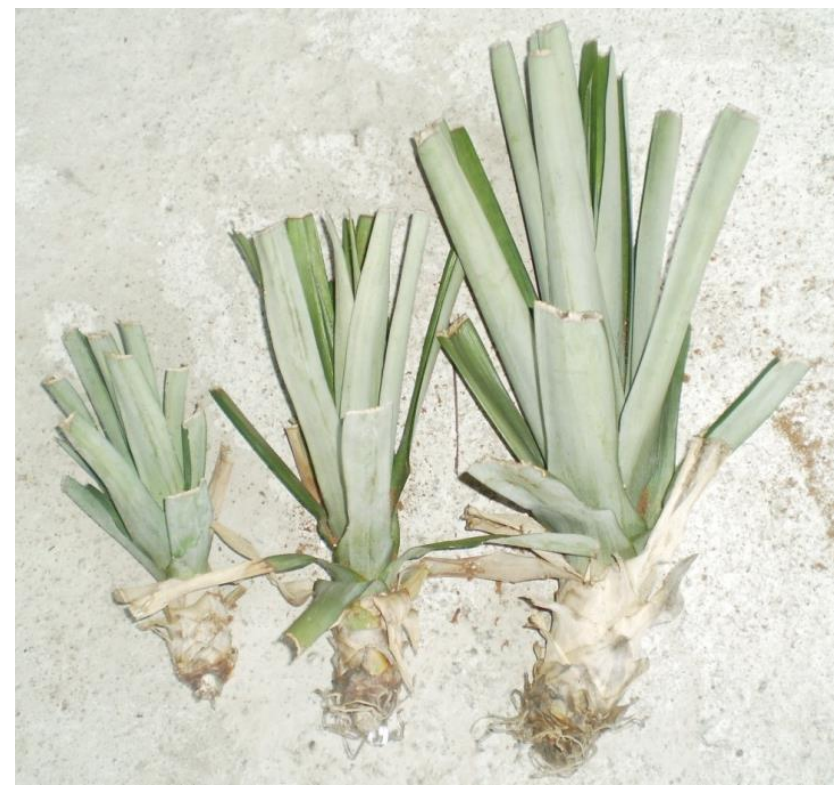

Figure 1. MD2 suckers; C grade (left); B grade (center); A grade (right).

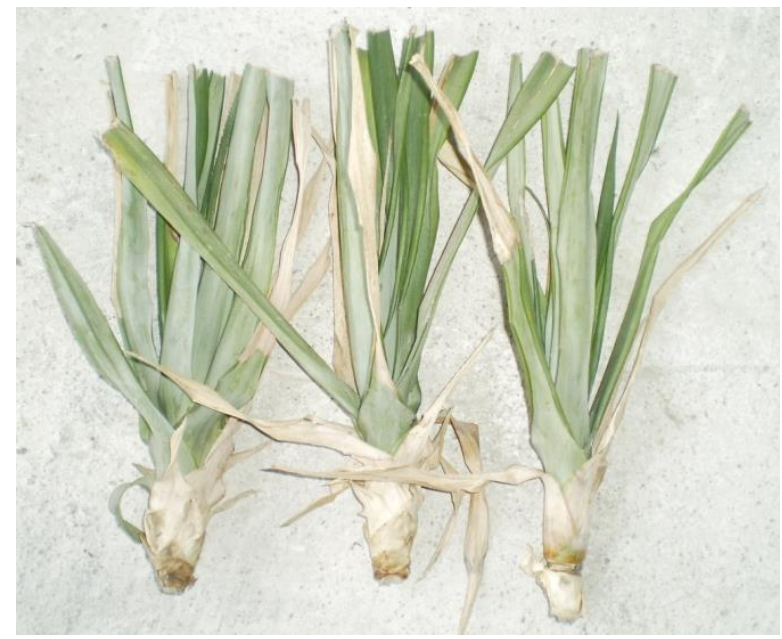

Figure 2. N36 suckers; A grade (left); B grade (center); C grade (right).

\section{Statistical Analysis}

The SAS computer program statistical analysis system (SAS Inst., 2002) univariate procedure was used to analyze the mean and standard deviation of the mentioned parameters for each grade and variety. Significant differences between grades from each variety for each parameter were also tested.

\section{Mechanical Transplanter}

The design improvements were based on a gripper-type mechanical transplanter (Figure 3). This machine was ground wheel driven, which meant that the mechanisms of the machine were generated by the rotation of the ground press wheel. This ground wheel moves the three roller chain systems that move the grippers. These grippers hold the seeds, or in this case, the pineapple suckers, before transferring them to the soil. A 
furrow opener is located at the front of the machine to open up the soil to ease transplanting. An operator seat and a seed tray are available for the operator to sit on and to load seeds to transfer to the grippers. The planting distance can be predetermined by changing the sprocket near the loading tray.

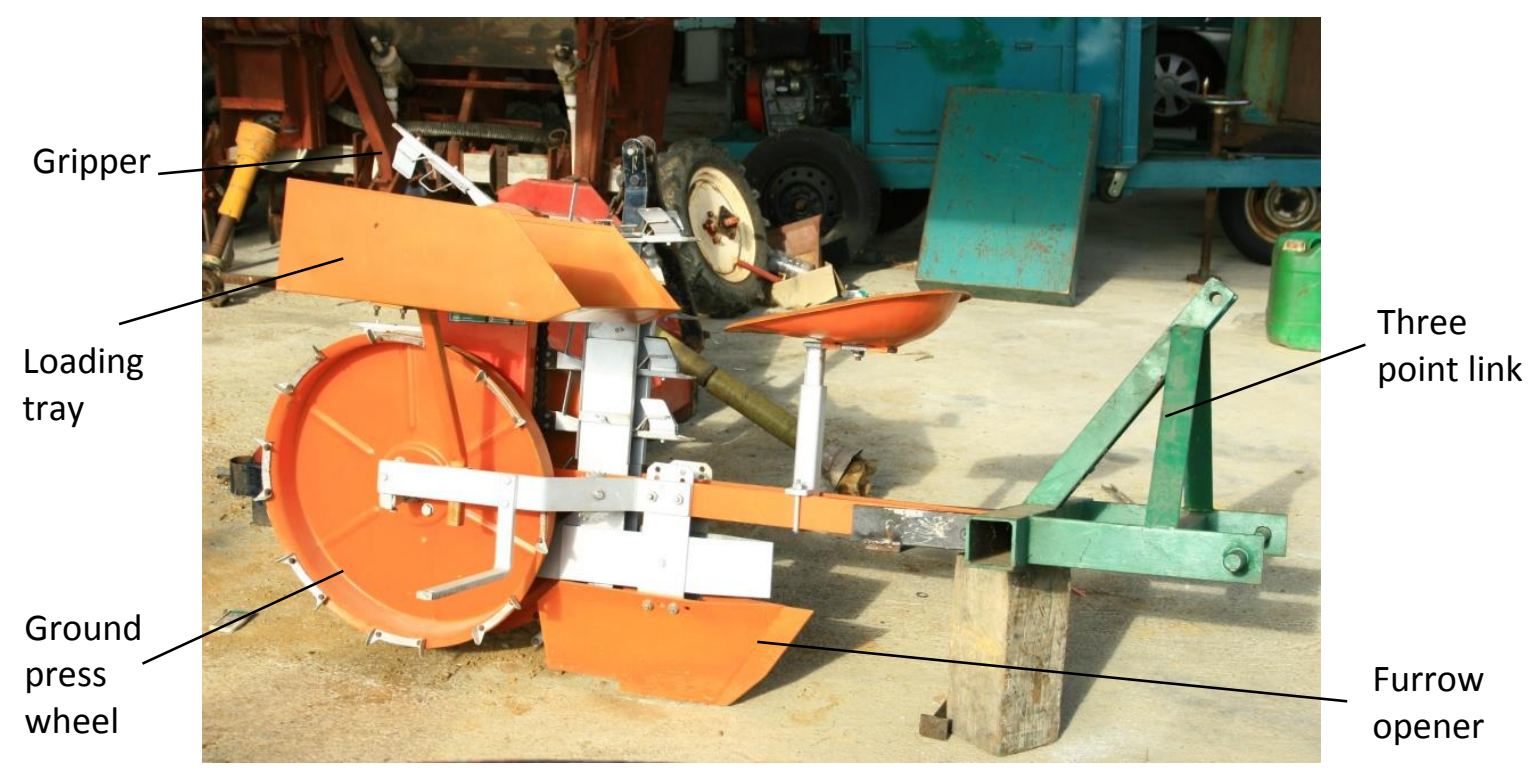

Figure 3. Major components of the mechanical transplanter

\section{Experiment Details}

A preliminary field test was done at the Mechanization and Automation Research Center (MA) research plot, MARDI, using the existing transplanter but with modification to the furrow opener. This machine or implement was attached to a 32.8 $\mathrm{kW}$ (44 hp) tractor (Kubota model L4400, Japan). All varieties and grades were tested during this test to observe the suitability of this transplanter for pineapple suckers. The quality of the transplanting was observed in terms of actual planting distance and the condition of the pineapple suckers after transplanting. The planting distance was set at $22 \mathrm{~cm}$ according to the sprocket teeth-planting distance table given by the manufacturer. The actual planting distance on the ground was measured. A transplanted pineapple sucker is considered to be in an acceptable condition when it is in an upright vertical position, and not slanted too much.

\section{RESULTS AND DISCUSSION}

\section{Pineapple Suckers Physical Parameters}

In this experiment, physical parameters of three grades from the MD2 and N36 varieties were measured and tabulated (Table 1). Statistical analysis showed that there were significant differences in diameter between each grade for the N36 variety $(\mathrm{p}<0.0001)$ and also for the MD2 variety $(\mathrm{p}<0.0001)$. There were also significant differences in length for the N36 variety $(p<0.0001)$ and MD2 variety $(p<0.0001)$. For the pineapple suckers' weight, there were significant differences between each grade for the N36 variety $(\mathrm{p}<0.0001)$ and also for the MD2 variety $(\mathrm{p}<0.0001)$. There were no significant differences in canopy for the two varieties. The average diameter for the A 
grade of the N36 variety was $3.9 \mathrm{~cm}$ with standard deviation of $0.5 \mathrm{~cm}$. For the B grade, the average diameter was $3.8 \mathrm{~cm}$ with standard deviation of $0.6 \mathrm{~cm}$ while the $\mathrm{C}$ grade had an average diameter of $3.2 \mathrm{~cm}$ with standard deviation of $0.3 \mathrm{~cm}$. For the MD2 variety, the average diameter for the A grade was larger than that of the N36 variety, which was $5.1 \mathrm{~cm}$ with standard deviation of $0.6 \mathrm{~cm}$. The B grade average diameter was $4.3 \mathrm{~cm}$ with standard deviation of $0.6 \mathrm{~cm}$, while the $\mathrm{C}$ grade was $3.9 \mathrm{~cm}$ with standard deviation of $0.6 \mathrm{~cm}$. The $\mathrm{C}$ grade diameter of the MD2 variety had the same average diameter as the A grade of the N36 variety.

Table 1. Statistical summary for all pineapple varieties and grades.

\begin{tabular}{lcccccc}
\hline & \multicolumn{5}{c}{ Variety and Grade } \\
& $\mathrm{A}$ & $\mathrm{N} 36$ & & & $\mathrm{MD} 2$ & \\
& & $\mathrm{~B}$ & $\mathrm{~A}$ & $\mathrm{~B}$ & $\mathrm{C}$ \\
\hline Diameter $(\mathrm{cm})$ & $3.9(0.5)$ & $3.8(0.6)$ & $3.2(0.3)$ & $5.1(0.6)$ & $4.3(0.6)$ & $3.9(0.6)$ \\
Length $(\mathrm{cm})$ & $60.6(6.7)$ & $50.1(4.3)$ & $40(6.1)$ & $67.8(8.4)$ & $48.7(6.6)$ & $36(6.5)$ \\
Weight $(\mathrm{g})$ & 339.4 & 146.8 & 149.4 & 664.2 & 349.2 & 226.2 \\
& $(110.5)$ & $(32.3)$ & $(40.6)$ & $(208.8)$ & $(88.9)$ & $(75.1)$ \\
Canopy $(\mathrm{cm})$ & $34.1(9.4)$ & $27.8(7.1)$ & $32.8(34.6)$ & $37.6(8.7)$ & $27(7.5)$ & $22.1(7.2)$ \\
\hline
\end{tabular}

The average length of the A grade of the N36 variety is $60.6 \mathrm{~cm}$ with standard deviation of $6.7 \mathrm{~cm}$. For the B grade, the average length was $50.1 \mathrm{~cm}$ with standard deviation of $4.3 \mathrm{~cm}$ while the $\mathrm{C}$ grade had an average length of $40 \mathrm{~cm}$ with standard deviation of $6.1 \mathrm{~cm}$. For the MD2 variety, the average length for the A grade was longer than that of the N36 variety, which was $67.8 \mathrm{~cm}$ with standard deviation of $8.4 \mathrm{~cm}$. The B grade average length was $48.7 \mathrm{~cm}$ with standard deviation of $6.6 \mathrm{~cm}$ while the $\mathrm{C}$ grade was $36 \mathrm{~cm}$ with standard deviation of $6.5 \mathrm{~cm}$. The $\mathrm{C}$ grade length of the MD2 variety had a shorter average length than the A grade of the N36 variety. The average weight for the A grade of the N36 variety is $339.4 \mathrm{~g}$ with standard deviation of $110.5 \mathrm{~g}$. For the B grade, the average weight was $146.8 \mathrm{~g}$ with standard deviation of $32.3 \mathrm{~g}$ while the $\mathrm{C}$ grade had an average weight of $149.4 \mathrm{~g}$ with standard deviation of $40.6 \mathrm{~g}$. For the MD2 variety, the average weight for the A grade was heavier than that of the N36 variety, which was $664.2 \mathrm{~g}$ with standard deviation of $208.8 \mathrm{~g}$. The B grade average weight was $349.2 \mathrm{~g}$ with standard deviation of $88.9 \mathrm{~g}$ while the $\mathrm{C}$ grade was $226.2 \mathrm{~g}$ with standard deviation of $75.1 \mathrm{~g}$. As expected, the $\mathrm{C}$ grade of the MD2 variety was heavier than the $\mathrm{C}$ grade of the $\mathrm{N} 36$ variety.

The physical parameters of the pineapple suckers were important because they affect the gripper design. It was necessary to obtain the smallest and largest diameter of the suckers, to ensure that the gripper can hold and grip the various sizes before they are transplanted. Suckers should be prevented from falling off the grippers. The length of each sucker was fixed to $30 \mathrm{~cm}$, because this is the common length of suckers used in pineapple plantations in Johor, so field workers were instructed to cut the suckers to this length. The suckers' weights were observed because the transplanter was previously used to transplant sweet potato cuttings, which are much lighter than pineapple suckers.

\section{Experiment Study}

A field trial was done using the current transplanter with modifications made only to the furrow opener and the planting distance. The furrow opener was widened from $8.9 \mathrm{~cm}$ 
to $10.2 \mathrm{~cm}$. The planting distance was set at $22 \mathrm{~cm}$ according to the sprocket teethplanting distance table given by the manufacturer. Although the suckers' length was cut to $30 \mathrm{~cm}$, the grippers only had space $25 \mathrm{~cm}$ in length. With allowable slippage of the ground press wheel, the targeted planting distance of $30 \mathrm{~cm}$ was achieved. The transplanted pineapple suckers were in an upright position, almost vertical and not slanting too much. The transplanter was mounted at the rear of the tractor. The forward travel speed was initially set at $0.8 \mathrm{~km} / \mathrm{h}$, which was the slowest travel speed that can be adjusted for the tractor. It was observed that, at this speed, the operator had difficulty in placing the pineapple suckers from the loading tray onto the grippers, because the gripper mechanism was too fast. The transplanter could easily transplant all grades of the N36 variety without any complications. The grippers had enough holding force to hold the pineapple suckers. The furrow opener was wide enough for the suckers to go through. However, for the MD2 variety, the A grade was unsuccessful at transplanting. The diameter of the suckers was too big for the machine. Their average diameter was $5.1 \mathrm{~cm}$ while the slot width was only $5 \mathrm{~cm}$. This meant that the slot had to be widened to cater for the A grade for the MD2 variety. The modified furrow opener succeeded in creating a furrow about 5 to $8 \mathrm{~cm}$ deep, to allow the pineapple suckers to be positioned vertically. The furrow depth could be adjusted by controlling the three-point hitch of the tractor. Previous tests showed that when using a minimum forward travel speed of 0.8 $\mathrm{km} / \mathrm{h}$, the operator had difficulty in loading the suckers onto the grippers. Different chain pitches were used for the three roller chain system used for the planting mechanism. The clippers also needed improvement to properly hold the pineapple suckers. The furrow opener was too small, and thus required widening. Design improvements proposed were: 1) changing the roller chain system configuration to reduce the sucker loading speed while maintaining planting distance, 2) changing the design of the grippers to suit pineapple suckers, and 3) widening the furrow opener.

\section{Design Improvements}

\section{Roller Chain System Change}

The roller chain systems that were currently being used by the transplanter were of different pitches (Figure 4). The first roller chain system, which was attached to the ground press wheel, used a $31.8 \mathrm{~mm}$ (1.25 in) pitch. The second roller chain system, which controls the planting distance of the machine, used a $12.5 \mathrm{~mm}(0.5 \mathrm{in})$ pitch roller chain. The third roller chain system controlled 10 grippers, using a $19.1 \mathrm{~mm}$ (0.75 in) pitch roller chain.

To use a uniform chain pitch for all three chain systems, the relationship between each sprocket in the system, targeted planting distance, distance between each gripper and ground press wheel diameter were investigated. The linear velocity of the chain system is calculated by measuring the sprocket pitch radius and the angular velocity of the chain system, as in Eq. (1):

$$
v=\omega r
$$

where $v$ is linear velocity in $\mathrm{m} / \mathrm{s}$, $\mathrm{r}$ is sprocket pitch radius in $\mathrm{m}$, $\omega$ is angular velocity in $\mathrm{rad} / \mathrm{s}$. 


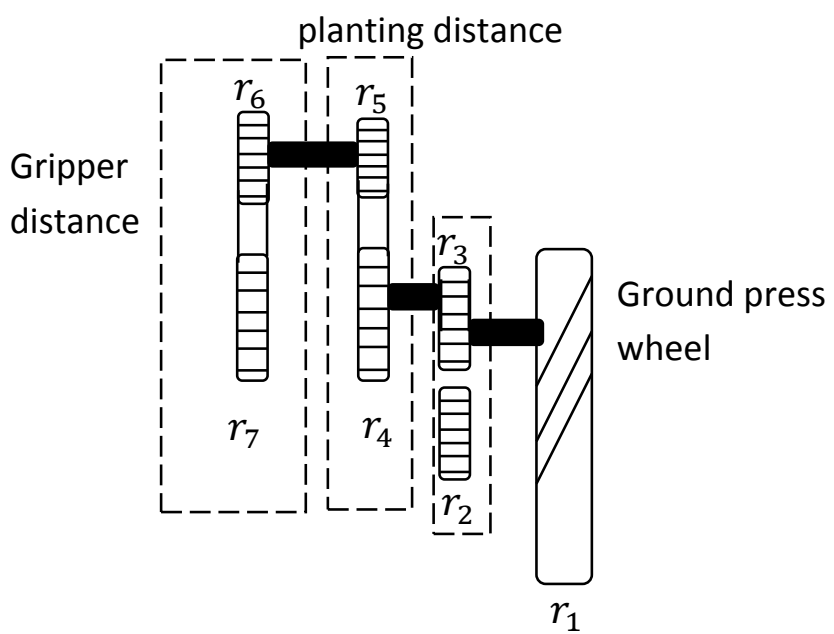

Figure 4. Gear arrangements to determine planting distance for the mechanical transplanter.

The targeted planting distance obtained by using the chain system is calculated by measuring each sprocket pitch radius and the distance between each gripper:

$$
S_{g}=\frac{S_{t} r_{1} r_{3} r_{5}}{r_{2} r_{4} r_{6}}
$$

where $S_{g}$ is targeted planting distance in $\mathrm{cm}$,

$S_{t}$ is distance between each gripper in $\mathrm{cm}$,

$r_{n}$ is the sprocket pitch radius for sprocket numbered n, except for $r_{1}$, which refers to the ground press wheel radius.

Referring to the Standard Book of Chains (2006), it was decided that the best chain pitch to use was $12.5 \mathrm{~mm}$ ( $0.5 \mathrm{in})$ chain. Therefore, the planting distance (before slippage) using the new pitch size was $23.8 \mathrm{~cm}$.

\section{Gripper design}

The current gripper was designed to accommodate cutting-based seedlings or plantlets such as sweet potato cuttings. The sweet potato cuttings used were 25 to 30 $\mathrm{cm}$ long. For transplanting pineapple suckers, the most suitable and most commonly used length was $30 \mathrm{~cm}$. The current gripper length is only $25 \mathrm{~cm}$. Furthermore, the gripper design is not suited for pineapple suckers. At one end of the gripper, where a piece of rubber and metal wire clamp at each side are located, is where the load of a pineapple sucker is greatest. A design change was needed in this location not only to properly hold the pineapple suckers in place on the gripper, but also to prevent the suckers from damage and falling out during transplanting.

\section{Gripper slot}

This gripper slot is a metal slot that helps the metal wires of the gripper to grip the suckers. Since the biggest diameter of the A grade of the MD2 variety is $5.7 \mathrm{~cm}$, and the gripper slot is only $5 \mathrm{~cm}$ wide, this gripper slot required widening. The proposed 
width of the slot was an increase to about $6 \mathrm{~cm}$. When widening the gripper slot, the mainframe bar also needed to be widened from $6.5 \mathrm{~cm}$ to about $7.5 \mathrm{~cm}$.

\section{Furrow opener}

The current furrow opener was not suitable for the grade A suckers from the MD2 variety. This was because the diameter of the suckers was too large to go through the furrow opener. Therefore, the width of the furrow opener was widened from $8.9 \mathrm{~cm}$ to $10.2 \mathrm{~cm}$.

\section{CONCLUSION}

Design improvements were made to the gripper-type transplanter to suit the transplanting of pineapple suckers. Physical parameters for pineapple suckers such as diameter, length, weight and canopy were measured. A preliminary test was conducted to observe the suitability of the gripper-type transplanter. It was observed that:

i The diameter of the pineapple suckers ranged from 3.4 to $5.7 \mathrm{~cm}$, which was important to determine whether the gripper-type transplanter could be used or not.

ii The length of the pineapple suckers of whatever variety will be cut to $30 \mathrm{~cm}$, as this is common practice by field workers.

iii The roller chain system will use $12.5 \mathrm{~mm}(0.5 \mathrm{in})$ chain for the whole chainsprocket system.

iv The gripper will be lengthened to $30 \mathrm{~cm}$ to accommodate the uniform pineapple sucker length. The gripper slot will also be widened to about $6 \mathrm{~cm}$.

$\mathrm{v}$ The furrow opener is widened from $8.9 \mathrm{~cm}$ to $10.2 \mathrm{~cm}$ to accommodate the biggest diameter of pineapple suckers.

These design improvements are intended to improve the workability of the mechanical transplanter for pineapple sucker transplantation.

\section{ACKNOWLEDGMENTS}

The authors wish to thank those who were directly or indirectly involved in this research at the Malaysian Agricultural Research and Development Institute (MARDI), This research was supported by assistance from the Mechanization \& Automation Research Center, MARDI support staff; Mr. Aris Abdullah, Mrs Norahshekin Abd Rahman, Mr Mohd Adli Ahmad Sayuti, Mr. Saleh Bardos, Mr Kasron Ahmad, Mr Ramlan Ismail, Mr Noor al Anuar Maskor and Mr Khairul Izwan Ayub. The authors would also like to thank MARDI for providing the funding for this project no JP-RM0351.

\section{REFERENCES}

ACA (2006). Standard Handbook of Chains: for power transmission and material handling. American Chain Association. L. L. Faulkner, ed. (2 $2^{\text {nd }}$ ed.). CRC Press.

Hamid, M. A., Ahmad, D., \& Rukunuddin, I. H. (2010). Performance of sweet potato transplanting machine on mineral and Bris Soils. Agricultural Mechanization in Asia, Africa and Latin America, 41, 55-59. 
JTP (2013). Fresh N36 Pineapple. Available at http://jtptrading.blogspot.com/2010/12/fresh-n36-pineapple.html. (Accessed 14 January 2013).

MPIB (Malaysian Pineapple Industry Board) (2012) .http://www.mpib.gov.my. (Accessed 7 June 2012).

MPIB (Malaysian Pineapple Industry Board) (2013). Nanas Manis MD2. Malaysian Pineapple Industry Board.

PEMANDU (Performance Management Delivery Unit) (2011). Chapter 15: Transitioning from Agriculture to Agribusiness. Economic Transformation Programme: A Roadmap for Malaysia. Pp. 513-550.

Rahim, H. A., Rohazrin, A. R., \& Al-Anuar, M. N. (2007). Development and performance of pineapple transplanter for commercial scale production on mineral soil. Proceedings of World Engineering Conference 2007, Penang.

Rahim H. A., Rohazrin, A. R., Khairul Fithri, A. R., \& Miswan, J. (2013). Manual Teknologi Penanaman Nanas Berjentera. MARDI.

SAS Inst. (2002). Statistical analysis system, version 9.3. Cary, N.C., USA. 